\title{
Estimate of the variability of the lysine requirement of growing pigs using the indicator amino acid oxidation technique ${ }^{1}$
}

\author{
R. F. Bertolo*2, S. Moehn*, P. B. Pencharz $\dagger$, and R. O. Ball ${ }^{* 3}$ \\ *Department of Agricultural, Food and Nutritional Science, University of Alberta, Edmonton, AB, \\ Canada T6G 2P5 and †Research Institute, Hospital for Sick Children, Toronto, ON, Canada M5G 1X8
}

\begin{abstract}
Although AA requirements for the mean in a population of growing pigs are well established, there are no direct estimates of their variability within the population. The indicator AA oxidation method allows repeated measurements in a short period of time so that the AA requirement can be determined for individual pigs. The objective was to determine the Lys requirement in individual pigs to derive a first estimate of the population mean requirement and its variability. Nine individually housed barrows (15 to $18 \mathrm{~kg}$ ) were surgically implanted with venous catheters for isotope infusion. Pigs were offered, in random order, isonitrogenous and isoenergetic diets with one of seven Lys concentrations (4.8 to $15.5 \mathrm{~g}$ of Lys/ $\mathrm{kg}$ diet, as-fed basis). The pigs were fed twice daily, except for study days when they received one-half of the daily allowance in eight equal hourly meals. After a validated minimum adaptation period, indicator (Phe) oxidation was determined for each dietary Lys level during a 4 -h primed, constant infusion of $\mathrm{L}-\left[1-{ }^{14} \mathrm{C}\right] \mathrm{Phe}$
\end{abstract}

at a rate of $464 \mathrm{kBq} / \mathrm{h}$. The Lys requirement was calculated using a two-phase linear regression crossover analysis within individual pigs. For each pig, Phe oxidation decreased linearly $(P<0.02)$ as the dietary Lys concentration increased until the requirement was reached; thereafter, Phe oxidation was not different. The true ileal digestible Lys requirement ranged from 7.5 to $10.6 \mathrm{~g} / \mathrm{kg}$ of diet (as-fed basis) for the nine animals. The mean requirement for all pigs was $9.1 \mathrm{~g} / \mathrm{d}$ (CV, $11.6 \%$ ) or $93.9 \%$ (CV, 9.8\%) of the predicted (NRC, 1998) requirement based on each pig's mean BW and energy intake. The measured and predicted requirements did not differ. The indicator AA oxidation method gave values for Lys requirement similar to conventional methods. The short ( $<3 \mathrm{wk}$ ) experimental period allows, for the first time, the estimate of population variability, which provides for more accurate calculation of the effect of altering Lys intake on herd performance and production economics. This method is suitable to use with all dietary indispensable AA.

Key Words: Amino Acid Oxidation, Lysine, Pig, Requirement, Variability

(C2005 American Society of Animal Science. All rights reserved.

J. Anim. Sci. 2005. 83:2535-2542

\section{Introduction}

Lysine requirements in pigs have been studied extensively (NRC, 1998), but no direct estimate of its variability is available. Lysine requirements depend mainly on sex, genotype, BW, feeding level, and environment (Noblet and Quiniou, 1999). Even when controlling for

\footnotetext{
${ }^{1}$ The study was funded by Alberta Pork and the Alberta Agric. Res. Inst. and Degussa AG. Degussa AG also generously provided synthetic amino acids and analyses of dietary amino acids. A fellowship for R. F. Bertolo was funded by Natural Sciences and Engineering Research Council of Canada.

${ }^{2}$ Current address: Dep. of Biochem., Memorial Univ. Newfoundland, St. John's, NL, Canada A1B 3X9.

${ }^{3}$ Correspondence: 4-10 Ag/Forestry Centre (phone: 780-492-7151; fax: 780-492-4265; e-mail: ron.ball@ualberta.ca).

Received January 29, 2005.

Accepted July 6, 2005.
}

these factors, differences in individual requirements have been shown in humans (Zello et al., 1993; Kriengsinyos et al., 2002) and poultry (Coleman et al., 2003). The importance of variability between individual animals was recognized (Lucas, 1960), but the lack of estimates of variation in pigs has been regretted (Pomar et al., 2003).

Traditional methods, such as growth rate or nitrogen balance assays, are unsuitable to determine requirements of individual growing animals, requiring prolonged periods of both adaptation to diets and measurement of response to obtain valid measurements. Testing six or seven dietary AA levels within an individual growing animal would require at least $2 \mathrm{mo}$, so the requirement would change substantially during the experiment. The indicator AA oxidation (IAAO) technique, which was developed in pigs (Kim et al., 1983; Ball and Bayley, 1984), has been widely used to determine AA requirements in pigs and humans (Brunton 
et al., 1998; Pencharz and Ball, 2003) and poultry (Coleman et al., 2003), although the IAAO requires specialized equipment and expensive material. The IAAO allows measurements to be made after an adaptation period of $2 \mathrm{~d}$ (Moehn et al., 2004b), so that sufficient levels of AA intake can be tested in a 2 -wk experiment without the animal changing its physiological state. By controlling animal BW, feed intake, and environmental conditions, the variability in requirements can be decreased to factors associated with the genotype of the individual animal. Thus, the objective of this experiment was to determine the Lys requirement of individual pigs and to derive an estimate of the intersubject and, hence, population variability.

\section{Materials and Methods}

\section{Animals and Study Protocol}

All procedures used in this study were approved by the Faculty's Animal Policy and Welfare Committee of the University of Alberta. Nine Genex Manor hybrid F1 (Genex Swine Group, Regina, SK, Canada) barrows (initial $\mathrm{BW}=19.1 \pm 2.7 \mathrm{~kg}$ ) were adapted to the experimental basal diets over $3 \mathrm{~d}$. Pigs were initially kept in pairs to minimize stress. After adaptation, pigs were fasted overnight, and surgery was performed the next morning. Pigs were induced (5\%) and maintained (2 to $3 \%$ ) with halothane anesthesia mixed with oxygen. Incisions were made on the inside of the thighs, and femoral veins were separated from the arteries with blunt dissection. Two Tygon (Fisher Scientific, Mississauga, ON, Canada) catheters were inserted into each femoral vein and advanced to the inferior vena cava just caudal to the heart. Catheters were tunneled under the skin from the incision sites to a point of exit between the shoulders on the back. Cotton-mesh netting was fitted around the pig's chest to secure the externalized catheters. Pigs were injected with antibiotics $(1.5 \mathrm{~mL}$ of sulfadoxine $200 \mathrm{mg} / \mathrm{mL}$; trimethoprim, $40 \mathrm{mg} / \mathrm{mL}$ ) and analgesic (buprenorphine, $0.1 \mathrm{mg} / \mathrm{kg}$ repeated 12 $\mathrm{h}$ after surgery) and left to recover in separate metabolic crates; all pigs were active and eating within $4 \mathrm{~h}$ after surgery. After $3 \mathrm{~d}$ of postsurgical recovery, pigs were fed test diets, and oxidation regimens were started. Each animal received, in random order without repeats, each of the diets providing one of seven Lys concentrations. Oxidation measurements were performed after 2 $\mathrm{d}$ of adaptation to a change of diet (Moehn et al., 2004b).

\section{Diets and Feeding}

The pigs were fed twice daily at 0800 and 1600 , except for the infusion days, when they received one-half of the daily ration divided in eight hourly meals; the remaining one-half of the daily ration was fed in the evening. Water was freely available at all times. This frequent feeding protocol produces a more stable isotope plateau than twice-daily feeding (Möhn et al., 2003).
Feed intake was restricted to $90 \mathrm{~g} / \mathrm{kg}^{0.75} \mathrm{BW}$ (as-fed basis). The feed was allocated based on the BW determined in the morning of study days after an overnight fast. Any feed not eaten was collected, dried, and weighed to obtain net feed intake. Diets were based on corn gluten meal and wheat for seven pigs (Pigs 1 to 7; Table 1). Individual Lys requirements were measured for two other pigs fed diets based on barley and soybean meal (Pigs 8 and 9; Table 1) to determine whether it was important to consider diet effects separately. Within ingredient types, two isoenergetic and isonitrogenous diets ("low Lys" and "high Lys") were formulated, differing only in their contents of Lys and Glu (to balance total N). All essential nutrients, except Lys, were provided at a level of at least $120 \%$ of their requirement according to NRC (1998). The low Lys and high Lys diets were used either on their own or mixed in the appropriate ratios to achieve the desired Lys concentrations. Diets provided Lys at estimated concentrations of $56,67,78,90,101,123$, and $145 \%$ of the NRC (1998) recommendation (4.8 to $15.5 \mathrm{~g}$ of Lys/kg of diet). Dietary AA concentrations (Table 2) were determined by Degussa AG (Hanau, Germany) using acid hydrolysis and ion-exchange chromatography with postcolumn derivatization with ninhydrin (Llames and Fontaine, 1994), except for Trp, which was determined by HPLC with fluorescence detection (extinction, 280 $\mathrm{nm}$; emission, $356 \mathrm{~nm}$ ) after alkaline hydrolysis with barium hydroxide octahydrate for $20 \mathrm{~h}$ at $110^{\circ} \mathrm{C}$ (Fontaine et al., 1998).

\section{Tracer Infusion and Breath Collection}

All pigs were subjected to repeated primed, constant, 4-h infusions. The pigs received a priming dose of 1.75 times the constant infusion rate of $464 \mathrm{kBq} / \mathrm{h}$ of L-[1${ }^{14}$ C]Phe (American Radiolabeled Chemicals, St. Louis, MO). The priming dose was injected manually via the femoral catheter over $1 \mathrm{~min}$. Immediately thereafter, the constant infusion was started using variable speed syringe pumps (Fisher Scientific, Mississauga, ON, Canada) using sterile saline to carry the isotope.

The equipment consisted of respiration chambers (1.2 $\mathrm{m}^{3}$ ) fitted with feeders and drinkers, air flow meters, and a series of gas-washing bottles for ${ }^{14} \mathrm{CO}_{2}$ collection. Air was drawn through these boxes by rotary vane air pumps (Gast Model 1023; Gast Mfg. Corp., Benton Harbour, MI) via an inlet at the rear and an outlet above the trough at rates of approximately $140 \mathrm{~L} / \mathrm{min}$. After passing through a cold water condenser to remove moisture from the air, the air flow was divided between a series of gas-washing bottles for $\mathrm{CO}_{2}$ collection and a line bypassing the collection. The flow rate through each diversion was measured continuously with two commercial air meters (Model AL 425; Canadian Meter Corp., Cambridge, ON, Canada). The gas-washing bottles were changed at 30-min intervals throughout the studies. The $\mathrm{CO}_{2}$ absorber (ethanolamine/2-methoxyethanol, $0.5 \mathrm{vol} / \mathrm{vol}$; Caledon Laboratory Chemicals, 
Table 1. Composition of experimental diets, as-fed basis

\begin{tabular}{|c|c|c|c|c|}
\hline \multirow[b]{2}{*}{ Ingredients, $\mathrm{g} / \mathrm{kg}$ of diet } & \multicolumn{2}{|c|}{ Wheat-corn gluten diet } & \multicolumn{2}{|c|}{ Barley-soybean meal diet } \\
\hline & Low Lys & High Lys & Low Lys & High Lys \\
\hline Barley & - & - & 501.00 & 501.00 \\
\hline Wheat & 400.00 & 400.00 & - & - \\
\hline Soybean meal, $44 \% \mathrm{CP}$ & - & - & 99.00 & 99.00 \\
\hline Corn gluten meal & 200.00 & 200.00 & - & - \\
\hline Starch & 135.00 & 135.00 & 109.85 & 109.85 \\
\hline Sugar & 136.00 & 136.00 & 109.00 & 109.00 \\
\hline Cellulose $^{\mathrm{a}}$ & - & - & 50.00 & 50.00 \\
\hline Canola oil & 50.00 & 50.00 & - & - \\
\hline L-His & 0.78 & 0.78 & 1.13 & 1.13 \\
\hline L-Ile & 1.00 & 1.00 & 2.16 & 2.16 \\
\hline L-Leu & - & - & 3.28 & 3.28 \\
\hline L-Lys $\cdot \mathrm{HCl}$ & 3.20 & 11.60 & - & 9.13 \\
\hline L-Cys & 0.90 & 0.90 & - & - \\
\hline DL-Met & - & - & 3.05 & 3.05 \\
\hline L-Phe & - & - & 2.35 & 2.35 \\
\hline L-Tyr & - & - & 2.03 & 2.03 \\
\hline L-Thr & 3.00 & 3.00 & 3.64 & 3.64 \\
\hline L-Trp & 1.32 & 1.32 & 0.71 & 0.71 \\
\hline L-Val & 1.90 & 1.90 & 2.80 & 2.80 \\
\hline L-Asp & - & - & 18.80 & 14.57 \\
\hline L-Glu & 8.40 & - & 18.90 & 14.00 \\
\hline Dicalcium phosphate & 23.0 & 23.0 & - & - \\
\hline Limestone & 11.0 & 11.0 & - & - \\
\hline Magnesium sulfate & 5.00 & 5.00 & - & - \\
\hline Sodium bicarbonate & 3.50 & 3.50 & - & - \\
\hline Sodium chloride & 1.50 & 1.50 & - & - \\
\hline Potassium bicarbonate & 3.50 & 3.50 & - & - \\
\hline Trace nutrient premix $^{b}$ & 11.00 & 11.00 & - & - \\
\hline Mineral-vitamin premix ${ }^{c}$ & - & - & 32.30 & 32.30 \\
\hline Choline chloride $\mathrm{d}^{\mathrm{d}}$ & - & - & 40.00 & 40.00 \\
\hline
\end{tabular}

\footnotetext{
aSolkafloc, Fiber Sales \& Development Corp., Urbana, OH.

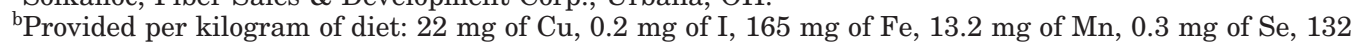
$\mathrm{mg}$ of $\mathrm{Zn}, 11,000 \mathrm{IU}$ of vitamin $\mathrm{A}, 1,100 \mathrm{IU}$ of vitamin $\mathrm{D}_{3}, 88 \mathrm{IU}$ of vitamin $\mathrm{E}, 2.2 \mathrm{mg}$ of vitamin $\mathrm{K}, 0.2 \mathrm{mg}$ of biotin, $1,100 \mathrm{mg}$ of choline, $1.8 \mathrm{mg}$ of folacin, $44 \mathrm{mg}$ of niacin, $27.5 \mathrm{mg}$ of pantothenic acid, $13.2 \mathrm{mg}$ of riboflavin, and $33 \mu \mathrm{g}$ of vitamin $\mathrm{B}_{12}$.

'Provided per kilogram of diet: $6.94 \mathrm{~g}$ of $\mathrm{Ca}, 2.71 \mathrm{~g}$ of available $\mathrm{P}, 1.55 \mathrm{~g}$ of $\mathrm{Na}, 0.32 \mathrm{~g}$ of $\mathrm{Mg}, 19.22 \mathrm{mg}$ of $\mathrm{Cu}, 0.32 \mathrm{mg}$ of I, $227 \mathrm{mg}$ of Fe, $51.7 \mathrm{mg}$ of Mn, $0.24 \mathrm{mg}$ of Se, $112 \mathrm{mg}$ of Zn, 9,690 IU of vitamin A, 1,131 IU of vitamin $\mathrm{D}_{3}, 50 \mathrm{IU}$ of vitamin $\mathrm{E}, 1.32 \mathrm{mg}$ of vitamin $\mathrm{K}, 0.194 \mathrm{mg}$ of biotin, $2.58 \mathrm{mg}$ of folacin, $30.7 \mathrm{mg}$ of niacin, $20.2 \mathrm{mg}$ of pantothenic acid, $5.7 \mathrm{mg}$ of riboflavin, and $28.4 \mu \mathrm{g}$ of vitamin $\mathrm{B}_{12}$.

${ }^{\mathrm{d}}$ Provided $2.9 \mathrm{~g}$ of choline/kg of diet.
}

Georgetown, ON, Canada) was weighed, sampled, and mixed with scintillation cocktail (Atomlight, Canberra Packard, Mississauga, ON, Canada) for measurement of ${ }^{14} \mathrm{CO}_{2}$. The samples were counted for $15 \mathrm{~min}$ or to an error of $2 \%$ in a liquid scintillation counter (Beckman LS3000; Beckman, Irvine, CA).

\section{Calculations}

Plateaus in breath ${ }^{14} \mathrm{CO}_{2}$ (expressed as a percentage of dose infused) were visually identified and confirmed by regression analysis, yielding a slope not significantly different from zero. The true ileal digestibility of Lys was calculated using digestibility estimates published by NRC (1998); L-Lys $\cdot \mathrm{HCl}$ was deemed $100 \%$ digestible (Susenbeth et al., 2001). The predicted true ileal digestible Lys requirement was calculated for each pig using the program published by NRC (1998), based on the mean BW and calculated energy intake for each individual pig.
Because the pigs were repeatedly dosed with radioactivity, the background radioactivity in breath was expected to increase; however, directly measuring this background radioactivity immediately before infusion was found to be highly variable because of increased activity with the first feeding. Therefore, a steady-state radioactive background was determined as described by Moehn et al. (2004b). Briefly, four growing pigs of the same genetic background and weight were subjected to the same feeding and isotope infusion regimens, after which the ${ }^{14} \mathrm{CO}_{2}$ expiration was determined at intervals representing the test protocol. The radioactive background in expired $\mathrm{CO}_{2}$ was expressed as a percentage of the cumulative dose infused:

$$
\begin{gathered}
\text { background }= \\
0.3379( \pm 0.0391) \times \mathrm{e}^{-0.1067( \pm 0.0348) \times \text { days since previous study }} .
\end{gathered}
$$

The ${ }^{14} \mathrm{CO}_{2}$ plateau values were corrected for background radioactivity according to this equation, and 
Table 2. Analyzed nutrient composition of ingredients, as-fed basis

\begin{tabular}{|c|c|c|c|c|}
\hline \multirow[b]{2}{*}{ Nutrient } & \multicolumn{2}{|c|}{ Wheat-corn gluten diet } & \multicolumn{2}{|c|}{ Barley-soybean meal diet } \\
\hline & Low Lys & High Lys & Low Lys & High Lys \\
\hline ME, MJ/kg (calculated) & 15.1 & 15.1 & 13.0 & 13.0 \\
\hline $\mathrm{CP}, \%$ & 17.6 & 17.2 & 14.7 & 14.7 \\
\hline \multicolumn{5}{|l|}{ Amino acids, $\mathrm{g} / \mathrm{kg}$} \\
\hline Arg & 9.6 & 9.2 & 6.0 & 5.9 \\
\hline His & 3.7 & 3.6 & 3.6 & 3.6 \\
\hline Ile & 6.5 & 6.4 & 6.2 & 6.2 \\
\hline Leu & 10.7 & 10.5 & 9.8 & 9.7 \\
\hline Lys & 5.0 & 15.5 & 4.8 & 13.1 \\
\hline True ileal digestibility, $\%^{\mathrm{a}}$ & 88.4 & 94.4 & 84.5 & 94.1 \\
\hline Met & 3.6 & 3.2 & 4.5 & 4.3 \\
\hline Phe & 7.6 & 7.7 & 7.3 & 7.2 \\
\hline Thr & 7.2 & 6.8 & 7.0 & 6.7 \\
\hline $\operatorname{Trp}$ & $\mathrm{ND}^{\mathrm{b}}$ & ND & 1.9 & 1.8 \\
\hline Val & 7.9 & 7.9 & 7.7 & 7.6 \\
\hline Ala & 4.5 & 4.4 & 4.4 & 4.4 \\
\hline Asp & 33.1 & 26.3 & 24.2 & 13.0 \\
\hline Cys & 3.3 & 3.0 & 2.0 & 2.0 \\
\hline Glu & 50.3 & 43.8 & 37.9 & 36.2 \\
\hline Gly & 4.5 & 4.5 & 4.1 & 4.1 \\
\hline Pro & 9.3 & 9.3 & 7.7 & 8.3 \\
\hline Ser & 4.9 & 4.8 & 4.6 & 4.6 \\
\hline
\end{tabular}

${ }^{\mathrm{a}}$ Calculated based on true ileal digestibilities of Lys in feedstuffs (NRC, 1998). L-Lys $\cdot H C l$ assumed $100 \%$ available.

${ }^{\mathrm{b}}$ Not determined.

oxidation rates were calculated from these corrected plateau values.

\section{Statistical Analyses}

The experimental units were individual animals. Data were tested for the influence of covariables (i.e., BW within and between pigs, dietary Phe content, and feed intake) using the MIXED procedure of SAS (SAS Inst., Inc., Cary, NC) with pig as random effect. Twoway interactions between these variables were tested and retained in the model if $P<0.10$. Lysine requirements were calculated from the original data and established for individual pigs using a two-phase linear regression crossover model, using the NLIN procedure of SAS, regressing oxidation rate on dietary Lys contents. The oxidation data points were partitioned iteratively between slope and plateau phase of the model until the residual mean square error was minimized. Requirements also were calculated as the intersection of a quadratic regression of oxidation rate on Lys intake with the plateau in oxidation (Baker et al., 2002). The requirements determined using the two-phase linear regression crossover model were tested for normal distribution using the UNIVARIATE procedure of SAS, and the resulting frequency distribution was plotted against dietary true ileal digestible Lys contents. The mean requirement of this sample of pigs and its variability were assessed by averaging the individual requirements. Measured and predicted requirements were compared using the Student's $t$-test. Relationships between parameters were assessed using Pearson's corre- lation coefficients. An $\alpha$ value of 0.05 was used to assess significance between means.

\section{Results}

During isotope infusions, the oxidation rate quickly increased until a plateau was obtained (Figure 1). Plateaus in oxidation were maintained for $4.7 \pm 0.1$ collection periods. Phenylalanine oxidation was between 4.0 and $19.7 \%$ (mean, $10.33 \%$ ) of the infused dose at steady state, depending on Lys intake. The mean of the standard errors during plateaus in oxidation was $0.82 \%$ of

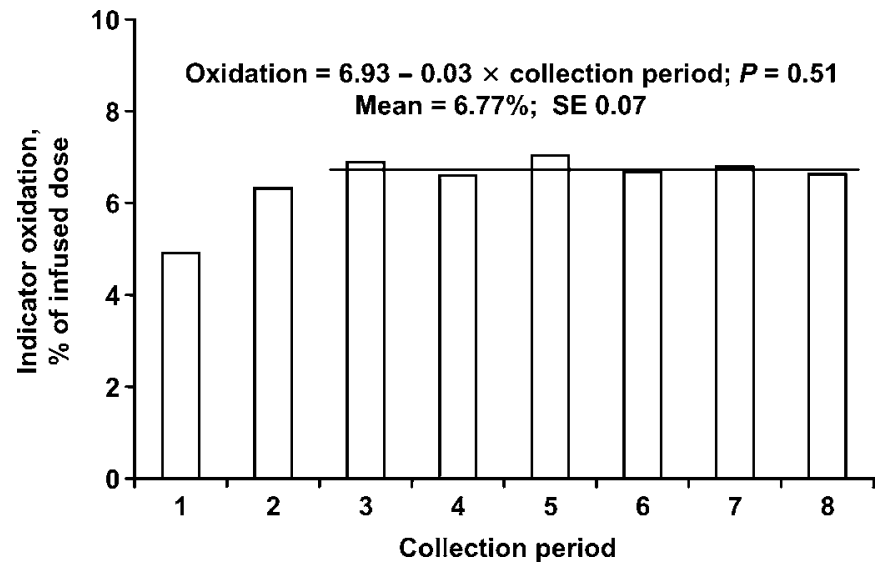

Figure 1. Example of a representative plateau in indicator amino acid oxidation for one pig at one dietary Lys content. Collection periods were $0.5 \mathrm{~h}$ each. 


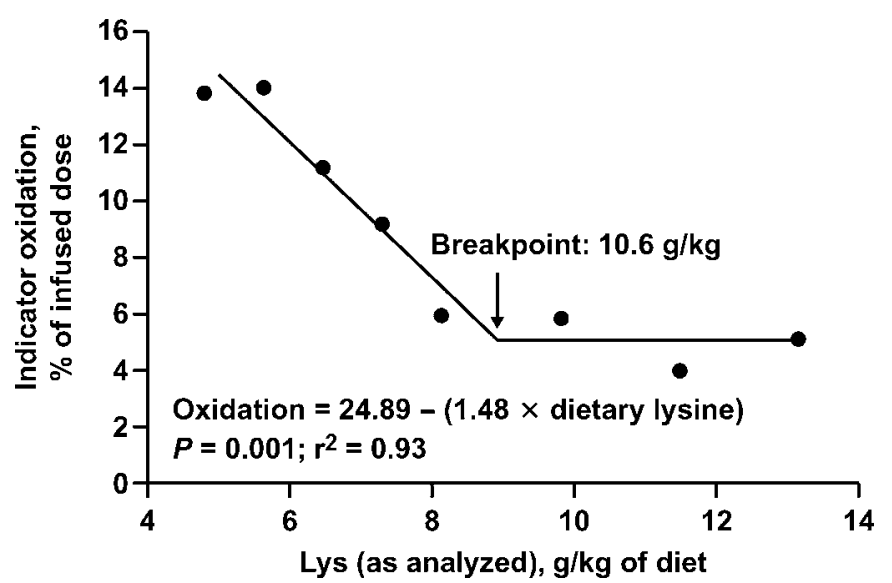

Figure 2. Indicator amino acid oxidation response to increasing dietary Lys concentration in an individual pig. Breakpoint was determined using two-phase linear regression crossover analysis.

the infused dose. A quadratic regression showed that dietary Lys contents explained 68\% of the variance of oxidation rates. Other main factors affecting oxidation rate were feed intake $(P=0.03)$ and BW nested within pig $(P=0.02)$. Oxidation rates tended to differ $(P=0.07)$ among days of study and BW $(P=0.09)$. Interactions between BW and day of study $(P=0.05)$, treatment group $(P=0.03)$, and feed intake $(P=0.06)$, as well as between treatment group and feed intake $(P=0.05)$, affected oxidation rates.

Figure 2 shows the typical response of oxidation to increasing dietary Lys contents. Phenylalanine oxidation decreased when dietary Lys intake increased until the requirement for Lys was reached; oxidation was not different between greater Lys intakes. The response of the oxidation rate to graded levels of dietary Lys in the other pigs followed the pattern shown in Figure 2. The two-phase linear regression model was significant for eight of the nine pigs $\left(P<0.02 ; \mathrm{r}^{2}=0.90\right.$ to 0.95$)$; although the model for Pig 7 only tended to fit the data $\left(P=0.098 ; r^{2}=0.47\right)$, it was included in summary statistics.

Each pig's Lys requirements are compared in Table 3 . The calculated requirement for true ileal digestible Lys (NRC, 1998) based on each pig's BW and feed intake ranged from 8.4 to $10.5 \mathrm{~g} / \mathrm{kg}$. The determined true ileal digestible Lys requirement using the two-phase linear regression crossover model was between 7.5 and 10.6 $\mathrm{g} / \mathrm{kg}$ with a mean of $9.09 \pm 1.06 \mathrm{~g} / \mathrm{kg}$. These measured Lys requirements ranged from 76.5 to $108.1 \%$ of the values predicted by NRC (1998), with a mean of 93.9 $\pm 9.2 \%$. The determined requirements were normally distributed (Figure 3), as shown by $66.7 \%$ of the data within one SD of the mean, and one data point each well below or above the bounds of one SD. Calculated according to the method recommended by Baker et al. (2002), the true ileal digestible Lys requirement was $10.3 \pm 1.09 \mathrm{~g} / \mathrm{kg}$ of diet. This requirement value was similar to the requirement according to NRC (1998), but greater $(P=0.02)$ than the requirement calculated using the two-phase linear regression crossover model. Both experimentally determined requirement values did not differ $(P>0.15)$ from the requirement calculated according to NRC (1998).

The variances of the requirements determined using the broken-line model did not differ $(P>0.34)$ from either of those calculated according to Baker et al. (2002) or predicted (NRC, 1998). In the broken-line model, the slope of the oxidation response was highly correlated to the determined requirements $(\mathrm{r}=0.85 ; P=$ 0.004); the steeper the slope, the lower the determined requirement. The oxidation at plateau was less well correlated ( $\mathrm{r}=0.59 ; P=0.097)$ to determined requirements.

\section{Discussion}

In the current experiment, we determined, for the first time the interanimal variability of the Lys requirement in growing pigs. Use of the IAAO technique allowed us to expose growing pigs to several levels of dietary Lys contents within a short time, so that the Lys requirement could be determined for each individual pig. We chose Lys as our test AA because of its importance as the first-limiting AA in most feedstuffs for swine and because of the abundance of data supporting estimates of Lys requirements in growing pigs (NRC, 1998).

The major factors affecting the requirement, such as sex, genotype, and environmental conditions (Noblet and Quiniou, 1999), were kept constant for all pigs. Data analyses showed that the oxidation rates were influenced by BW within and among pigs and by the pigs' feed intakes. These are key factors determining the AA requirements of pigs (NRC, 1998; Noblet and Quiniou, 1999). Therefore, the requirement was expressed as a percentage of the requirement calculated according to NRC (1998), using the calculated ME intake and BW of each individual pig. Expressing the Lys requirement relative to the predicted requirements according to NRC (1998) accounted for the effect of BW and feed intake on the requirement. These relative values, therefore, represent the estimate of the interanimal variability of Lys requirements.

The IAAO-determined Lys requirements agreed well with the NRC estimates with a mean of $93.9 \%$ of the NRC estimates and a SD of 9.2 (Table 3). The confidence interval in these pigs ( $8.8 \%$ of the mean requirement) is considerably smaller than the intersubject variation observed for Lys requirements in adult humans, which ranges from 31 to $50 \%$ of the mean requirement (Zello et al., 1993; Kriengsinyos et al., 2002; Kurpad et al., 2003). The greater intersubject variability of requirements in humans is probably due to the differences in genetic variability in each species. In prelaying broilerbreeders, the $95 \%$ confidence interval was $31 \%$ of the mean requirement (Coleman et al., 2003); however, 
Table 3. Body weight, daily feed intake, and calculated vs. determined Lys requirements of individual pigs

\begin{tabular}{|c|c|c|c|c|c|c|c|c|}
\hline \multirow[b]{2}{*}{$\mathrm{Pig}^{\mathrm{b}}$} & \multirow[b]{2}{*}{ No. ${ }^{c}$} & \multicolumn{2}{|c|}{$\mathrm{BW}, \mathrm{kg}$} & \multicolumn{2}{|c|}{ Feed intake, $\mathrm{g}$} & \multicolumn{3}{|c|}{ Lys requirement, $\mathrm{g} / \mathrm{kg}$ of $\mathrm{feed}^{\mathrm{a}}$} \\
\hline & & Mean & $\mathrm{SE}$ & Mean & $\mathrm{SE}$ & NRC & Determined & $\%$ of NRC \\
\hline 1 & 7 & 20.4 & 1.6 & 973 & 128 & 10.5 & 10.0 & 95.2 \\
\hline 2 & 7 & 19.7 & 1.5 & 946 & 120 & 10.5 & 8.8 & 84.1 \\
\hline 3 & 7 & 25.0 & 1.2 & 986 & 37 & 10.0 & 9.8 & 98.1 \\
\hline 4 & 7 & 26.1 & 1.2 & 1,009 & 39 & 9.9 & 9.9 & 100.0 \\
\hline 5 & 7 & 24.5 & 0.8 & 969 & 29 & 10.0 & 9.1 & 91.2 \\
\hline 6 & 7 & 27.4 & 1.7 & 1,059 & 46 & 9.8 & 7.5 & 76.5 \\
\hline 7 & 7 & 27.4 & 1.7 & 1,063 & 47 & 9.8 & 10.6 & 108.1 \\
\hline 8 & 8 & 22.4 & 1.7 & 895 & 40 & 8.5 & 7.9 & 93.3 \\
\hline 9 & 8 & 24.2 & 1.4 & 948 & 32 & 8.4 & 8.2 & 98.1 \\
\hline Mean & & 24.1 & & 982 & & 9.71 & 9.09 & 93.9 \\
\hline SD & & 4.5 & & 173 & & 0.76 & 1.06 & 9.23 \\
\hline $\mathrm{CV}, \%$ & & & & & & 7.8 & 11.7 & 9.8 \\
\hline
\end{tabular}

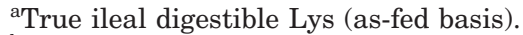

${ }^{\text {bPigs }} 1$ to 7 = wheat-corn gluten meal diet; Pigs 8 and $9=$ barley-soybean meal diet.

${ }^{\mathrm{c}}$ Number of observations within pig.

those data were derived from four birds only and apply to a different species and physiological state (i.e., nongrowing maintenance requirements). Estimates of the variability of Lys requirements in pigs have been reported as $6 \%$ of the mean requirement for week-old parenterally fed piglets (House et al., 1998) and as a $95 \%$ confidence interval of $2.3 \%$ of the mean requirement in growing pigs (Lin et al., 1986). However, the estimates by House et al. (1998) and Lin et al. (1986), similar to other previous estimates, do not represent a true estimate of intersubject variability, but rather the statistical error involved in estimating the requirement. In the present study, the confidence interval of $8.8 \%$ of the mean requirement provides, for the first time, a direct estimate of interindividual variation for growing pigs. This low variation emphasizes the high selection pressure in domestic pigs and also confirms the formulas developed by NRC to calculate requirements (1998).

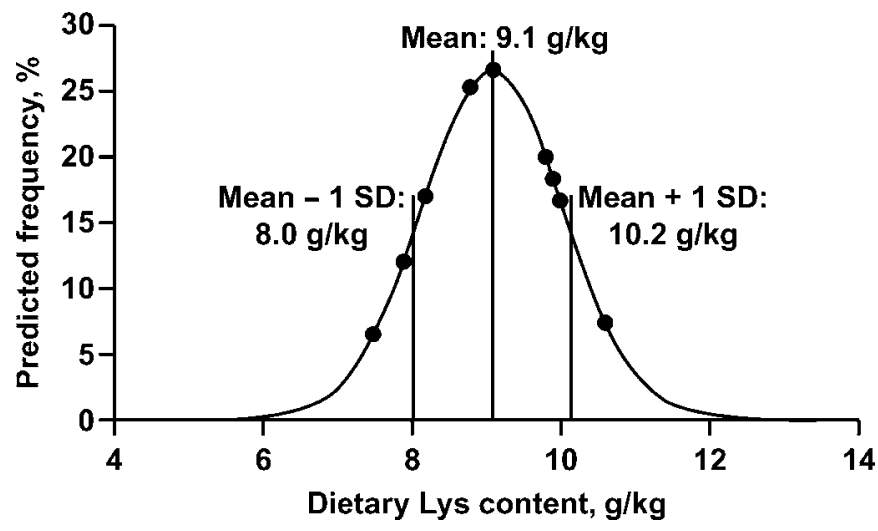

Figure 3. Frequency distribution of the predicted Lys requirements in growing pigs. Measured requirements for individual pigs are indicated by
Variability in the Lys requirement may be associated with individual differences in the efficiency of Lys utilization or with differences in the ratio of lipid to protein deposition. Weis et al. (2004) found that the litter from which experimental animals originated accounted for some of the variation in the whole-body lipid-to-protein ratio. Conversely, a lower rate of inevitable Lys oxidation would lead, as was observed in the current experiment, to a greater slope for the decrease in indicator oxidation when Lys intake was below the requirement. Although lower rates of inevitable Lys catabolism have been associated with greater rates of maximum protein deposition (Moehn et al., 2004a), the unexplained variation in Lys catabolism was still $22 \%$. We hypothesized that this remaining variation in inevitable Lys catabolism is due to the quantity and activity of the Lys catabolic enzymes. In any case, the indicator oxidation response of a pig to increasing dietary Lys concentrations may be used as a criterion to select more efficient pigs with lower Lys requirements. Because such response data could be collected within a few weeks, pigs with such advantageous qualities could be selected early for future breeding or could be tested in multiple physiological phases.

Knowledge of the mean requirement and its variability are very valuable because they can be used to calculate the economics of altering the Lys supply. For example, the cost vs. benefit of decreasing or increasing dietary Lys by $1 \mathrm{~g}$ can be calculated using the change in percentage of pigs that will not be receiving their requirement. The expected change in barn or group performance (e.g., weight gain, feed efficiency, lean yield) can be balanced against the change in feed cost, thereby giving the pork industry a new tool to determine the optimum feeding strategy under differing cost/ revenue scenarios.

The mean Lys requirement found in this study (9.1 $\mathrm{g}$ of true ileal digestible Lys/kg of diet) was similar to 
the requirement calculated according to the NRC (1998; $9.7 \mathrm{~g} / \mathrm{kg}$ of true ileal digestible Lys), which is based predominantly on growth and $\mathrm{N}$ balance studies. Requirements should be independent of the analytical technique chosen for determination (Pencharz and Ball, 2003). Comparing AA requirements in humans obtained by IAAO and by the $\mathrm{N}$ balance technique, Pencharz and Ball (2003) found no difference caused by the method used, although requirements obtained by the IAAO technique seemed numerically greater. In the current experiment, the IAAO-determined average requirement was numerically less (by 6\%) than the predicted average requirement (NRC, 1998), but appreciably less than the requirement calculated using the quadratic equations recommended by Baker et al. (2002). These differences are likely due to the statistical model used to calculate requirements, whereas the numerical difference between the broken-line requirements and those according to NRC (1998) also may be caused by analysis of data collected across many pigs vs. those collected within individual pigs. In humans, the estimated protein requirement tends to be greater when obtained by the overall approach of fitting all available data (similar to the approach used by NRC) compared with the requirement determined by averaging individual requirements (Rand et al., 2003). The higher NRC value also may be partly due to a difference in the dietary NE content. In corn gluten meal, the protein quality is rather poor, supplying a large excess of several AA, which might have led to increased energy losses in urine and as heat. This results in an overestimation of ME, which would have led to an overestimation in the Lys requirement using NRC (1998) calculations. We chose to use a wheat-corn gluten meal diet to get as low a Lys concentration as possible for the basal diet. For comparison, we determined individual Lys requirements for two pigs fed diets based on barley and soybean meal. In these pigs, the Lys requirements (93 and 98\% of NRC) were well within the confidence interval of the other seven pigs (86 to $101 \%$ of NRC). Other diets based on various feedstuffs and other genetic lines of pigs may need to be studied to establish whether the IAAO-determined Lys requirement is consistently lower than the corresponding NRC estimates.

\section{Implications}

The indicator amino acid oxidation technique and the short ( $<3 \mathrm{wk}$ ) experimental period required allows, for the first time, the generation of a direct estimate of population variability for an amino acid requirement. Knowledge of population variability allows the accurate calculation of the effect of choosing a specified "safety factor" on herd performance and can be used as a tool to adjust the feeding strategy to differing cost/revenue scenarios to maximize the margin over feed cost. Furthermore, the individual lysine requirement, as well as the oxidation response to increasing intakes of lysine, can be used as criteria for the selection of pigs that make more efficient use of dietary lysine. Although we have only reported individual variation in lysine requirement, this method is suitable to use with all dietary indispensable amino acids.

\section{Literature Cited}

Baker, D. H., A. B. Batal, T. M. Parr, N. R. Augspurger, and C. M. Parsons. 2002. Ideal ratio (relative to lysine) of tryptophan, threonine, isoleucine and valine for chicks during the second and third weeks posthatch. Poult. Sci. 81:485-494.

Ball, R. O., and H. S. Bayley. 1984. Tryptophan requirement of the 2.5 -kg piglet determined by the oxidation of an indicator amino acid. J. Nutr. 114:1741-1746.

Brunton, J. A., R. O. Ball, and P. B. Pencharz. 1998. Determination of amino acid requirements by indicator amino acid oxidation: applications in health and disease. Curr. Opin. Clin. Nutr. Metab. Care 1:449-453.

Coleman, R. A., R. F. Bertolo, S. Moehn, M. A. Leslie, R. O. Ball, and D. R. Korver. 2003. Lysine requirements of pre-lay broiler breeder pullets: Determination by indicator amino acid oxidation. J. Nutr. 133:2826-2829.

Fontaine, J., S. Bech-Andersen, U. Butikofer, and I. De FroidmontGortz. 1998. Determination of tryptophan in feed by HPLCdevelopment of an optimal hydrolysis and extraction procedure by the EU commission DG XII in three international collaborative studies. Agribiol. Res. 51:97-108.

House, J. D., P. B. Pencharz, and R. O. Ball. 1998. Lysine requirement of neonatal piglets receiving total parenteral nutrition as determined by oxidation of the indicator amino acid L- $\left[1-{ }^{14} \mathrm{C}\right]$ phenylalanine. Am. J. Clin. Nutr. 67:67-73.

Kim, K.-I., I. McMillan, and H. S. Bayley. 1983. Determination of amino acid requirements of young pigs using an indicator amino acid. Br. J. Nutr. 50:369-382.

Kriengsinyos, W., L. J. Wykes, R. O. Ball, and P. B. Pencharz. 2002. Oral and intravenous tracer protocols of the indicator amino acid oxidation method provide the same estimate of the lysine requirement in healthy men. J. Nutr. 132:2251-2257.

Kurpad, A. V., M. M. Regan, T. Raj, J. Vasudevan, R. Kuriyan, J. Gnanou, and V. R. Young. 2003. Lysine requirements of chronically undernourished adult Indian men, measured by a 24 -h indicator amino acid oxidation and balance technique. Am. J. Clin. Nutr. 77:101-108.

Lin, F. D., T. K. Smith, and H. S. Bayley. 1986. Influence of dietary lysine concentration on the oxidation of an indicator amino acid by growing boars. J. Anim. Sci. 63:1179-1183.

Llames, C. R., and J. Fontaine. 1994. Determination of amino acids in feeds: Collaborative study. J. AOAC Int. 77:1362-1402.

Lucas, I. A. M. 1960. Problems of the science of pig feeding. Pages 32-50 in Proc. Conf. Agric. Res. Workers and Agric. Economists, Pig Industry Development Authority, London, UK.

Moehn, S., R. O. Ball, M. F. Fuller, A. M. Gillis, and C. F. M. de Lange. 2004a. Growth potential, but not body weight or moderate limitation of lysine intake, affects inevitable lysine catabolism in growing pigs. J. Nutr. 134:2287-2292.

Moehn, S., R. F. P. Bertolo, P. B. Pencharz, and R. O. Ball. 2004b. Indicator amino acid oxidation responds rapidly to changes in lysine or protein intake in growing and adult pigs. J. Nutr. 134:836-841.

Möhn, S., M. F. Fuller, R. O. Ball, and C. F. M. de Lange. 2003. Feeding frequency and tracer do not affect direct estimates of lysine oxidation in the growing pig. J. Nutr. 133:3504-3508.

Noblet, J., and N. Quiniou. 1999. Principaux facteurs de variation du besoin en acides amines du porc en croissance. Techni-Porc. 22:9-16.

NRC. 1998. Nutrient Requirements of Swine. 10th ed. Natl. Acad. Press, Washington, DC.

Pencharz, P. B., and R. O. Ball. 2003. Different approaches to define individual amino acid requirements. Annu. Rev. Nutr. 23:101-116. 
Pomar, C., I. Kyriazakis, G. C. Emmans, and P. W. Knap. 2003. Modelling stochasticity: Dealing with populations rather than individual pigs. J. Anim. Sci. 81(E. Suppl.):E178-E186.

Rand, W. M., P. L. Pellett, and V. R. Young. 2003. Meta-analysis of nitrogen balance studies for estimating protein requirements in healthy adults. Am. J. Clin. Nutr. 77:109-127.

Susenbeth, A., A. Agunbiade, and J. Dohms. 2001. Bioavailability of lysine of several protein sources determined by the slope-ratio assay in pigs. Pages 133-137 in Workshop on Protein Feed for Animal Production in Central and Eastern Europe, Rennes,
France. C. Fevrier, A. Aumaitre, F. Habe, T. Vares, and M. Zjalic, eds. Wageningen Pers, Wageningen, The Netherlands.

Weis, R. N., S. H. Birkett, P. C. H. Morel, and C. F. M. de Lange. 2004. Effects of energy intake and body weight on physical and chemical body composition in growing entire male pigs. J. Anim. Sci. 82:109-121.

Zello, G. A., P. B. Pencharz, and R. O. Ball. 1993. Dietary lysine requirement of young adult males determined by oxidation of L- $\left[1-{ }^{14}\right.$ C $]$ phenylalanine. Am. J. Physiol. Endocrinol. Metab. 264:E677-E685. 